\title{
Notes on the vocalizations of Eastern Mountain Greenbul (Andropadus nigriceps)
}

\section{Peter Boesman}

In the following we briefly analyze and compare voice of the different races of Eastern Mountain Greenbul (Andropadus nigriceps). We also try to quantify the extent of any vocal differences using the criteria proposed by Tobias et al. (2010), as a support for taxonomic review. We have made use of sound recordings available on-line from Xeno Canto (XC) and Macaulay Library (ML).

A comparison of voice per race based on available recordings illustrated with sonograms:

\section{kikuyuensis}

song

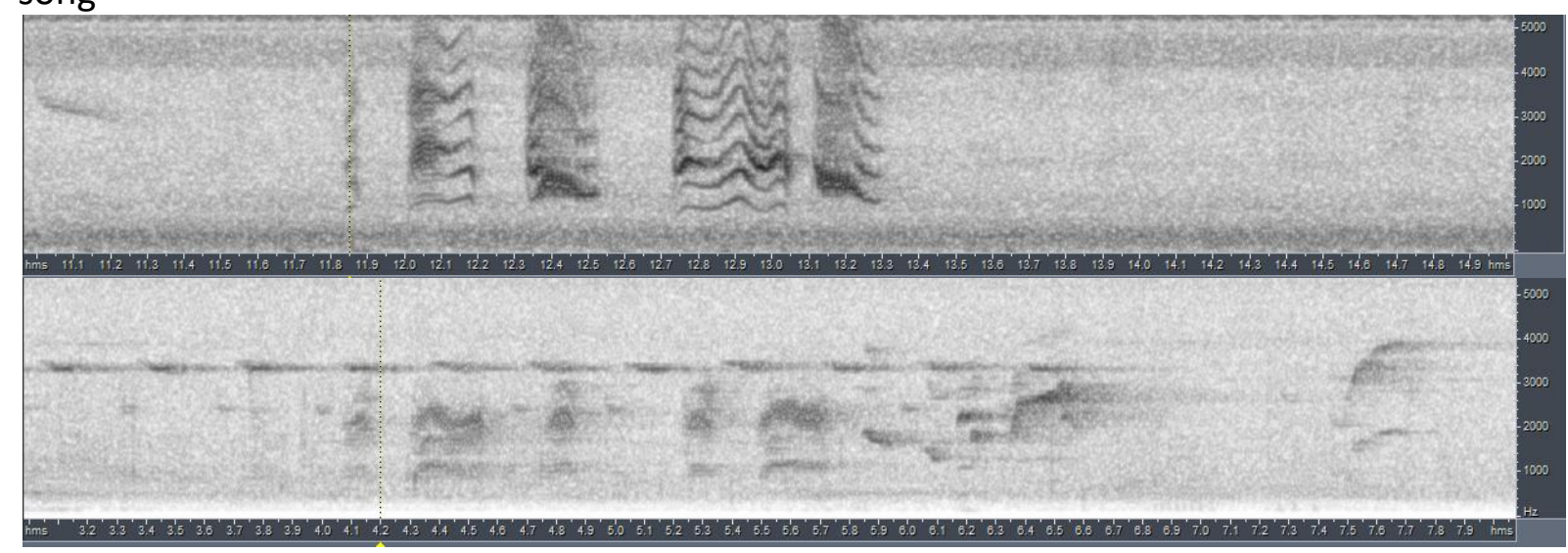

song??

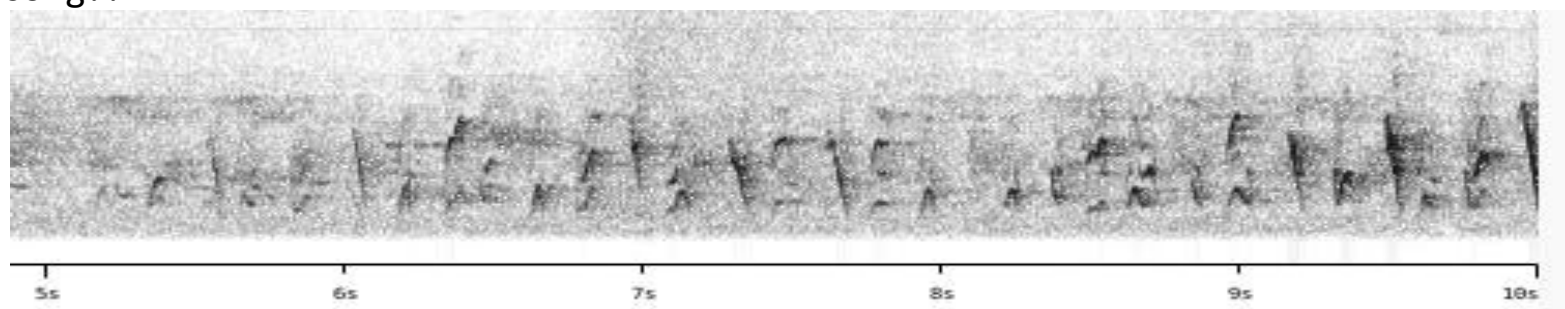

usumbarae

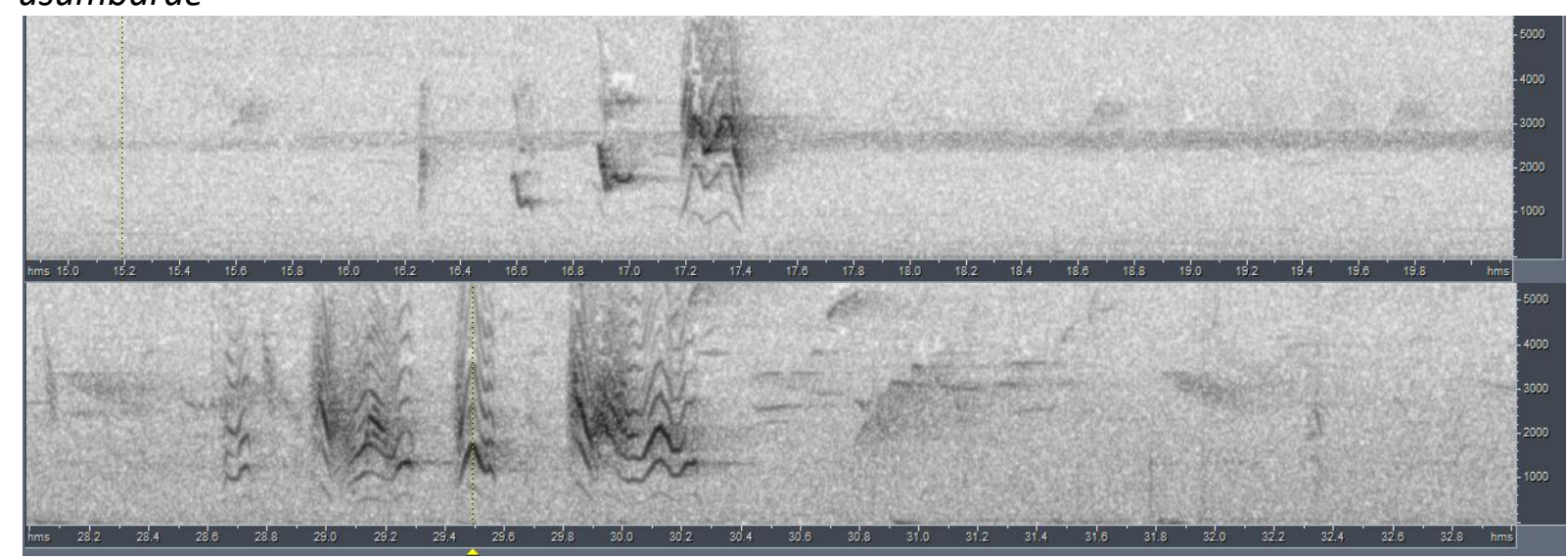




\section{HANDBOOK OF THE \\ BIRDSPF THE WORLD Alwe}

\section{ORNITHOLOGICAL NOTES}

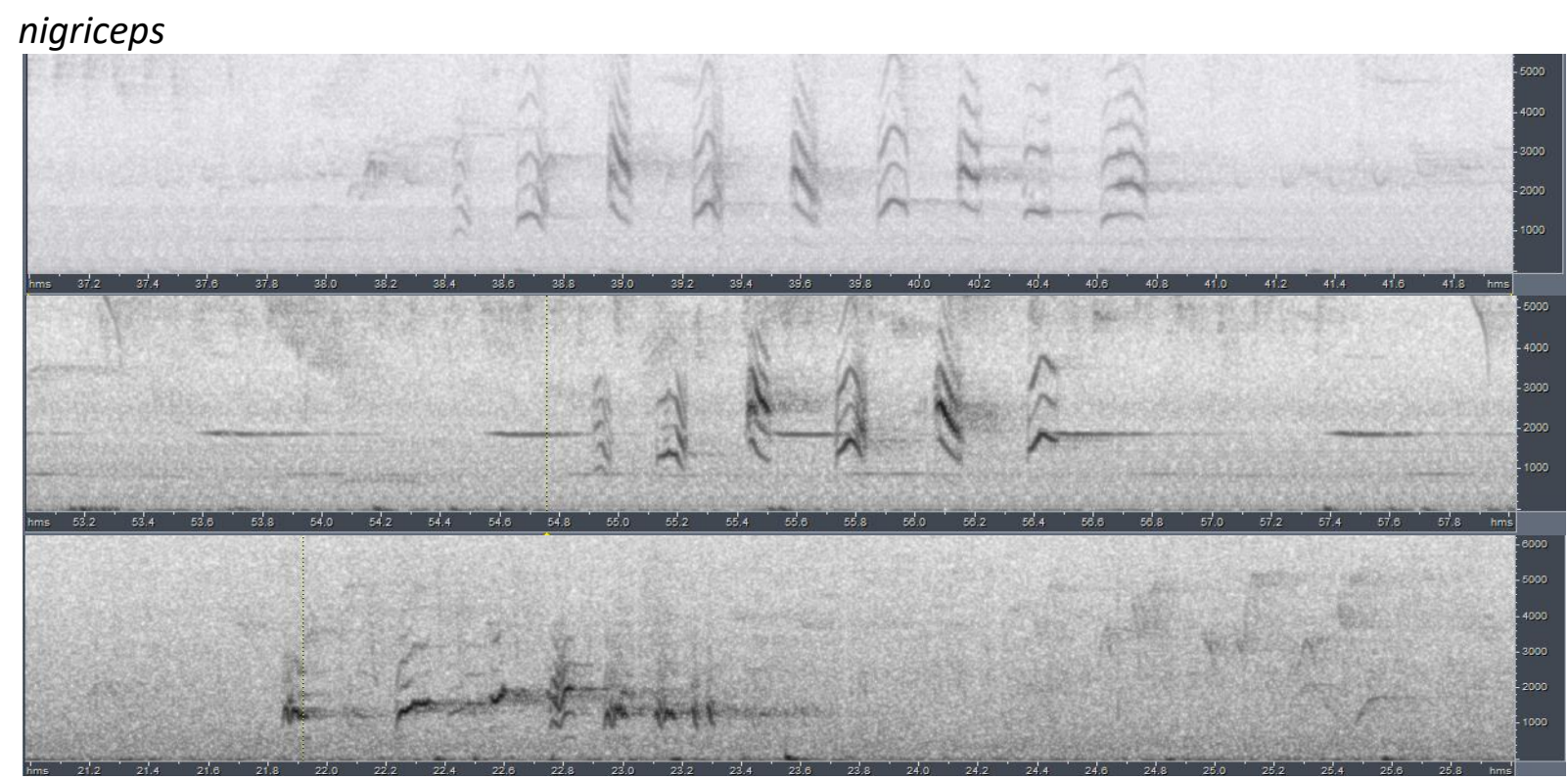

chlorigula

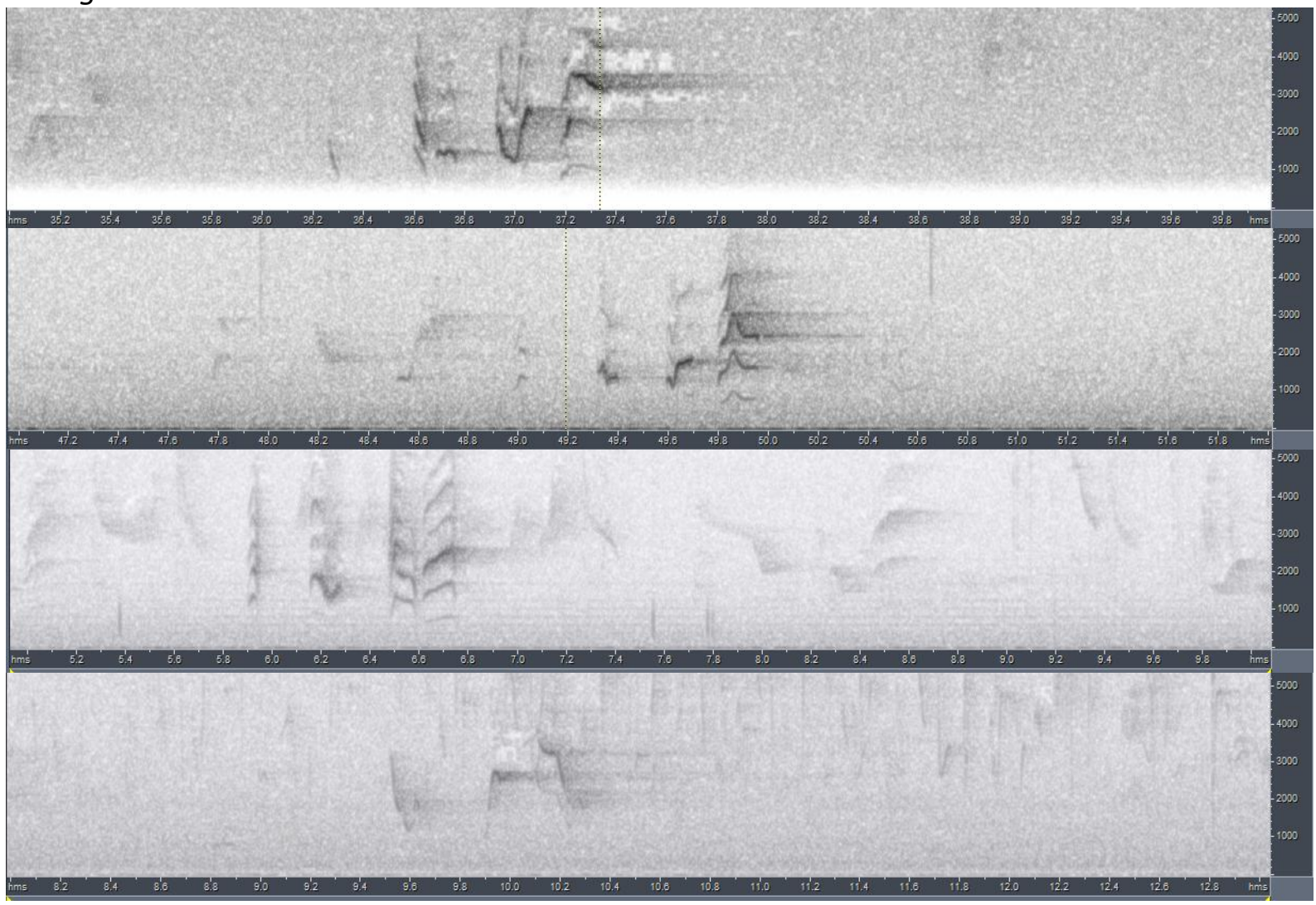

neumanni $(n=1)$

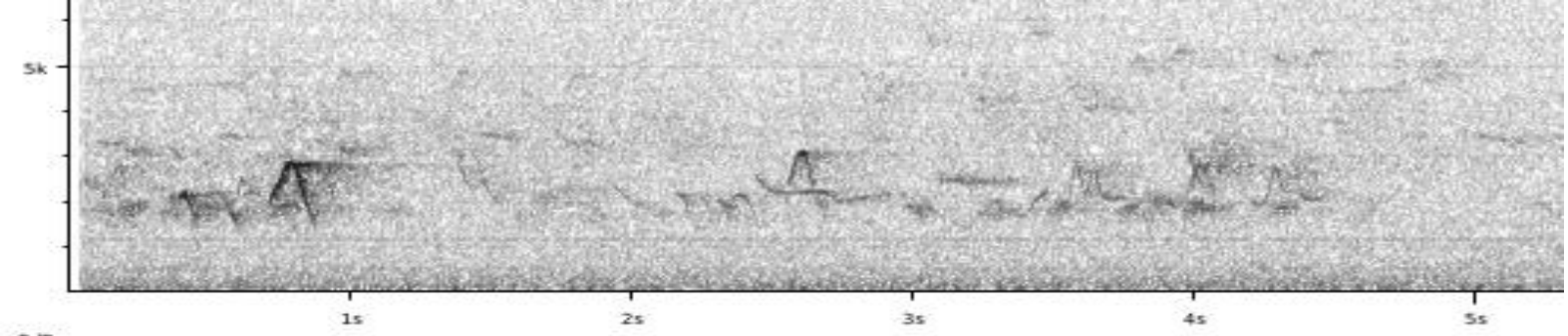




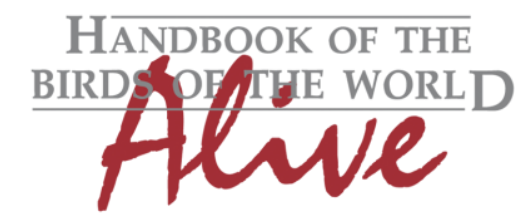

\section{ORNITHOLOGICAL NOTES}
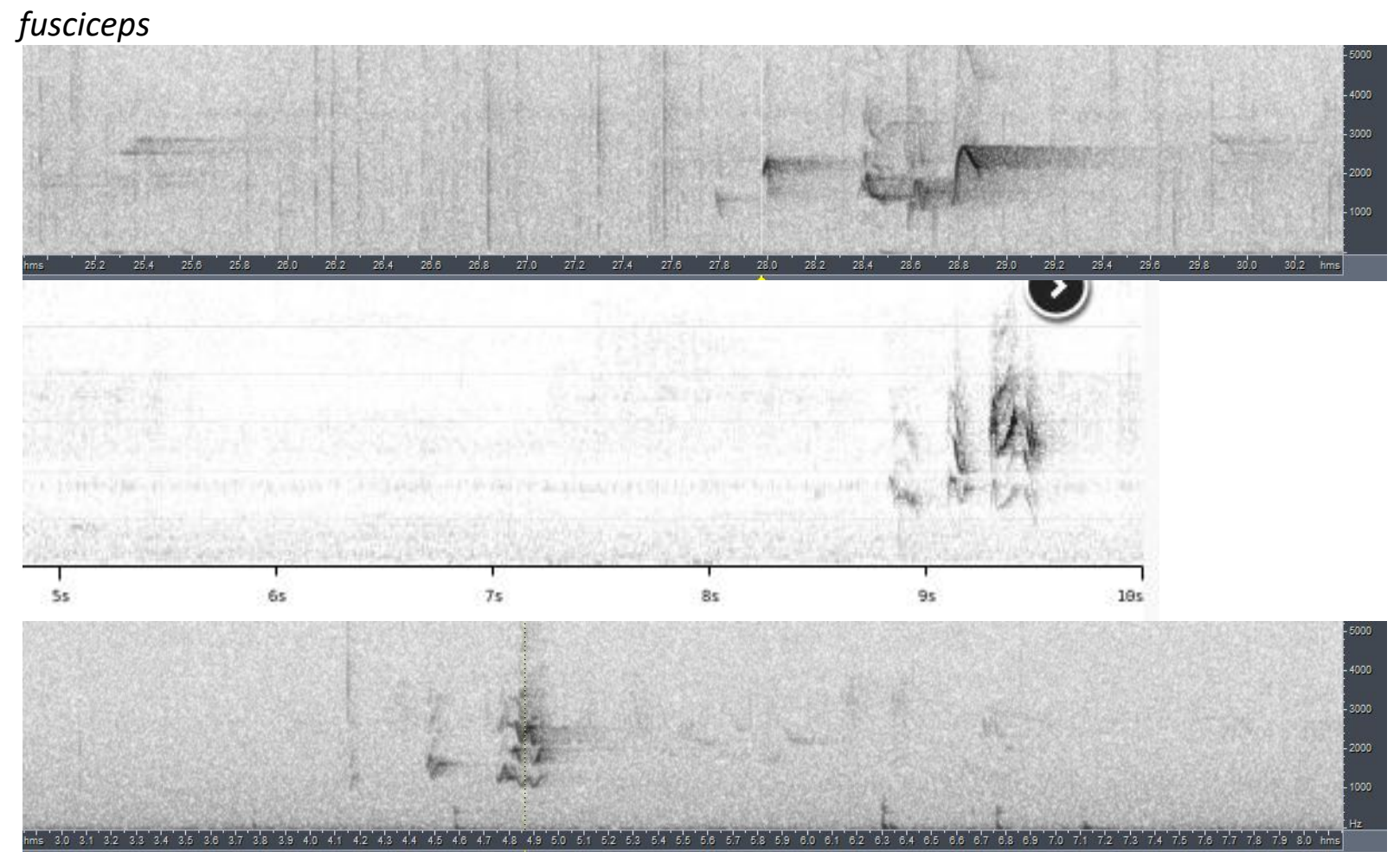

Vocalizations seem to be somewhat clinal from $\mathrm{N}$ to $\mathrm{S}$ :

kikuyuensis has two song types: a very nasal phrase of 5 drawn-out notes and a more cheerful phrase of a few staccato notes ending with a louder upslurred note.

usumbarae has also similar two song types, actually showing very little difference (compare e.g. sonogram 1 of kikuyuensis with sonogram 2 of usumbarae).

nigriceps on the other hand may have only a single song type, a rhythmic phrase of some 6-9 short nasal notes, sometimes with acceleration towards the end, and on about the same pitch (a bit surprising as this taxon is sometimes grouped with usumbarae).

all other races seem to have only a single song type of the 'melodious type' consisting of a few staccato notes ending with a louder higher-pitched note. From the few available examples, it would probably not be possible to safely tell these other races apart from one another vocally, given there is quite some variation.

Based on voice alone, separation into three groups seems to be the most logical classification (obviously based on the limited number of recordings available): kikuyuensis/usumbarae, nigriceps and all other races.

Quantification of vocal differences requires clarity about what exactly are homologous vocalizations, which is not fully clear at this point, but it can be expected that vocal scores among the different groups are in the range 2-4 .

This note was finalized on 18th February 2016, using sound recordings available on-line at that moment. We would like to thank in particular the sound recordists who placed their recordings for this species on XC and ML: Jason Anderson, James Bradley, Rolf de By, Louis Hansen, Peter Kaestner, Frank Lambert, Linda Macaulay, David Moyer, Ted Parker and Martin St-Michel. 


\section{References}

Tobias, J.A., Seddon, N., Spottiswoode, C.N., Pilgrim, J.D., Fishpool, L.D.C. \& Collar, N.J. (2010). Quantitative criteria for species delimitation. Ibis 152(4): 724-746.

\section{Recommended citation}

Boesman, P. (2016). Notes on the vocalizations of Eastern Mountain Greenbul (Andropadus nigriceps). HBW Alive Ornithological Note 421. In: Handbook of the Birds of the World Alive. Lynx Edicions, Barcelona. (retrieved from http://www.hbw.com/node/1253832 on 7 December 2016). 